\title{
ANÁLISIS PSICOLÓGICO DE LA PELÍCULA “THE WOODSMAN” (EL LEÑADOR)
}

\author{
PSYCHOLOGICAL ANALYSIS OF "THE WOODSMAN" MOVIE
}

Manuel Arboccó de los Heros ${ }^{1}$

\section{RESUMEN}

El siguiente artículo es un intento por presentar el análisis psicológico de una película de Nicole Kassell, director de cine de los Estados Unidos, titulada "The Woodsman" o "El leñador", película que trata la historia de Walter, un ex reo que pasa doce años en prisión por delitos sexuales cometidos a niñas y luego de cumplir su pena, sale de la cárcel para ingresar en una sociedad en la que no se ubica, a la que no siente pertenecer y que le recordará continuamente lo patológico de su ser. Revisaremos, a partir de lo mostrado en la película, las particularidades en la experiencia del protagonista, el diagnóstico de pedofilia, posibilidades de su desarrollo psicosexual infantil, su vínculo con una compañera de trabajo y el papel de la sociedad en casos similares a este.

\section{Palabras clave}

Trastorno, pedofilia, sexualidad infantil, psicoterapia

\section{ABSTRACT}

The following article is an attempt to present the psychological analysis of a film by Nicole Kassell, director of cinema of the United States, entitled "The Woodsman" or "The lumberjack", a movie that is the story of Walter, a former inmate who spends twelve years in prison for sexual crimes committed to girls and after completing his sentence, released from prison to enter in a society which is not located which does not feel belong and which remind continuously the pathological of his being. From what is shown in the film, the particularities in the experience of the protagonist, the diagnosis of pedophilia, will review possibilities of his childhood psychosexual development, its link with a colleague and the role of the society in similar cases.

\section{Keywords}

Disorder, pedophilia, child sexuality, psychotherapy

"El cine no es un arte que filma vida, el cine está entre el arte y la vida" Jean Luc Goddard

\footnotetext{
Psicólogo. Profesor Universitario. Egresado de la Maestría en Psicología por la Universidad Nacional Mayor de San Marcos. Psicoterapeuta Humanista.

2 Ficha técnica de la película

Nombre: The Woodsman (El leñador)

Dirección: Nicole Kassell

Guión: Nicole Kassell, Steven Fechter

Protagonistas: Kevin Bacon, Benjamin Bratt, Kyra, Sedgwyck, Michael Shannon, Mos Def, Kevin Rice, Hannah Pilkes

País: EEUU / Año: 2004 / Género: Drama
} 


\section{INTRODUCCIÓN}

Este artículo propone una serie de reflexiones a partir de la observación de la película "The Woodsman" (El leñador). La película relata la historia de Walter, un ex condenado a prisión por delitos sexuales a menores de edad. La película se inicia en el momento que Walter sale de prisión.

Doce años de cárcel por abusar sexualmente de niñas entre los 10 y los 12 años. Sale con libertad supervisada y nuevamente debe continuar con una vida de libertad y de responsabilidades, esto último también lo perdió, al menos parcialmente, en esos largos doce años de prisión. La primera tarea es la reinserción laboral, para eso ingresa a trabajar en una maderera en tareas ciertamente conocidas por él.

En cuanto a su familia, solo se menciona en la película una hermana, dos años menor, la cual no quiere saber nada de él y solo hay un vínculo con su cuñado Carlos, esposo de esta hermana, que lo visita una vez que Walter sale de prisión. Curiosamente Walter al salir se aloja en un departamento que se ubica frente a una escuela primaria.

Ocurre una rápida identificación entre Walter y Vickie, una compañera de trabajo, poco femenina, algo tosca, arrebatada, directa $e$ independiente. Analizaremos las causas de esa unión.

Paralelamente a su vida laboral, Walter debe asistir a terapia psicológica. Muestra hostilidad y mucho miedo y resistencia a esta labor. Desde un inicio de la película el rostro de Walter refleja cansancio, incredulidad, desasosiego y fastidio.

\section{SALIR PARA VOLVER A ENTRAR: COMPULSIÓN A LA REPETICIÓN}

¿Por qué ir a vivir al frente de una escuela primaria? Es porque como dice el protagonista, ¿es el único lugar donde aceptan mi dinero? Quizá eso más la tan mencionada "compulsión a la repetición" freudiana. Un fantasma del cual el protagonista no puede desprenderse. $\mathrm{Al}$ ir en círculos, como en un tío vivo ${ }^{3}$ (como dice Walter en un momento de asociaciones libres con su psicólogo) volvemos a confrontar las cosas que vivimos por primera vez. Puede ser una suerte de prueba que se hace a sí mismo o una trampa inconsciente.

En cuanto a Vickie, ¿por qué una mujer aceptaría un trabajo típicamente masculino como el de una maderera? Y es que Vickie tiene su propia historia, ella tuvo que hacerse fuerte, luego de sobrevivir a tres hermanos que la empleaban para satisfacer sus deseos sexuales genitales mientras era una niña.

Vickie se acerca a Walter y busca iniciar una relación con él. Al conseguirlo, pasan a tener inmediatamente relaciones sexuales con lo que nos preguntamos ¿Es Walter realmente un pedófilo?

Veamos. La gente que presenta pedofilia declara sentirse atraída por los niños dentro de un margen de edad particular. (DSM IV, p. 540). La literatura indica que la frecuencia del comportamiento pedofílico fluctúa a menudo con el estrés psicosocial y esto se muestra en la película.

La pedofilia (o pederastia para hablar con propiedad) es considerada una parafilia $y$ una parafilia se define como un trastorno psicosexual que se caracteriza por fantasías, urgencias o conductas sexuales intensas, recurrentes, que incluyen un contenido sexual atípico o inaceptable.

Luego de revisar estos criterios, aceptamos que Walter es un pedófilo de tipo heterosexual no exclusivo a niñas.

Walter inicia una relación con Vickie, pasa el tiempo con ella, beben unas cervezas, rien juntos, sin embargo sus recuerdos lo persiguen y no puede entregarse completamente a la tranquilidad y posibilidades de su presente. Es un tipo atormentado por sus recuerdos y sus culpas. $Y$ es en momentos de estrés donde aparecen con más fuerza sus deseos pedofílicos.

\footnotetext{
3 Recreo de feria que consiste en varios asientos colocados en un círculo giratorio (DRAE).
} 


\section{Criterios para diagnosticar pedofilia según el DSM IV ${ }^{4}$}

A. Durante un período de al menos 6 meses, fantasías sexuales recurrentes y altamente excitantes, impulsos sexuales o comportamientos que implican actividad sexual con niños prepúberes o niños algo mayores (generalmente de 13 años o menos).

B. Las fantasías, los impulsos sexuales o los comportamientos provocan malestar clínicamente significativo o deterioro social, laboral o de otras áreas importantes de la actividad del individuo.

C. La persona tiene al menos 16 años y es por lo menos 5 años mayor que el niño o los niños del Criterio A.

Nota: No debe incluirse a individuos en las últimas etapas de la adolescencia que se relacionan con personas de 12 o 13 años.

\section{Criterios para diagnosticar pedofilia según el CIE $10^{5}$}

El CIE 10 habla de paidofilia, y dice: Se trata de una preferencia sexual por los niños, normalmente de edad prepuberal o de la pubertad temprana. Algunos de los afectados sienten atracción únicamente por las chicas, otros únicamente por los chicos y otros están interesados por ambos sexos

Walter le cuenta el motivo de su encarcelamiento y ella pareciera sentir curiosidad y compasión o lástima por él, más no temor ni rechazo, respuestas que bien pueden ser consideradas comunes en casos como estos. Recordemos que de todas las conductas sexualmente prohibidas, junto con el incesto, la pedofilia ocupa un lugar importante en sociedades como las de Walter, es algo abominable, un tabú.

Regresemos a Vickie, ¿tiene esto que ver con su propio pasado? Conocido es por los psicólogos que la elección de amigos y, más aún, de parejas no es casual. No es un asunto de suerte sino de guiones que se entrelazan al más puro estilo de la propuesta de Eric Berne y su Análisis Transaccional ${ }^{6}$. Un guión, para el Dr. Berne es un programa en curso, desarrollado en la primera infancia bajo la influencia parental, que dirige la conducta del individuo en los aspectos más importantes de su vida. Los guiones generalmente están basados en ilusiones infantiles que pueden persistir toda una vida (Berne, 1988. p. 41).

Es como el guión de un actor, se ciñe a él para representar un pape, un rol. Al establecerlo en una edad muy temprana -niñez- suele no ser muy consciente del mismo y repite acciones y decisiones equivocadas llegando a establecer posiciones existenciales dañinas para sí y para los demás (Berne, 1985).

Por su parte, Walter sigue sintiéndose malo o enfermo, se pregunta ¿cuándo seré normal? Pareciera que no puede aceptar que su castigo acabó, que ya pagó su error o delito. Sigue dudando de sí y por ende de los demás, hay una actitud paranoica, de desconfianza y recelo ante los demás, inclusive de los que parecen amistosos.

Su psicólogo le propone escribir lo que piensa o siente, pero él no puede expresarlo

4 DSM- IV: Manual Diagnóstico y estadístico de las enfermedades mentales de la asociación Psiquiátrica Americana, Cuarta revisión.

5 CIE 10: Clasificación Estadística Internacional de enfermedades y problemas relacionados con la salud, décima revisión de la Organización Mundial de la Salud (OMS).

6 Análisis Transaccional: (AT) es una escuela de psicología enfocada al mejoramiento personal y social, fundada por el psiquiatra Eric Berne (1910-1970). 
por escrito, está bloqueado, atascado en lo ocurrido, pareciera que sigue encarcelado aún.

La presencia de su cuñado Carlos es curiosa, ¿será que Walter proyecta sus temores o deseos en él? Recordemos esa escena cuando Walter le pregunta si siente algo por su propia hija, desatando una respuesta violenta en Carlos; ¿o Carlos -pareciera también que- lo provoca, lo estimula, lo confronta?, por ejemplo al hablarle de lo sexys que se visten las jóvenes adolescentes hoy día. Pienso en la posibilidad de que esta escena toque un tabú paterno: el mirar en algún momento a las hijas ya no como niñas sino como mujeres. Esta situación suele ser reprimida en personas sanas $y$ adaptadas, más no en aquellos hombres con deficiencias y perturbaciones ocurridas en su desarrollo psicosexual. Este tópico ha sido ya trabajado extensamente por las propuestas psicodinámicas.

Llegado este punto (el deseo por el objeto prohibido) cabe mencionar los límites entre lo consciente y lo inconsciente, entre lo permitido y lo no aceptado. La necesaria represión de los deseos más oscuros y perversos en aras de poder convivir medianamente en paz con los otros, como bien diría Freud. La tentación del disfrute sexual con un(a) joven para el adulto que, de haber pasado un proceso psicosexual sin sobresaltos, puede luego ser reprimido o sublimado en alguna de sus manifestaciones, pero que en el caso de Walter no ocurre viendo crecer en su interior una curiosidad que llegó al punto de satisfacer la pulsión en la realidad, con el consiguiente castigo moral y real. ¿Ha visto usted amable lector, esas prendas que reproducen un vestuario escolar, siendo vendidas como herramientas de seducción y de juegos sexuales para las parejas? Si las escolares (adolescentes o púberes) no son vistas como objetos sexuales, entonces ¿cuál sería la motivación de involucrar ese estímulo asociado (la faldita, la blusita de colegiala) al pasatiempo amoroso adulto? Aparecen también canciones populares sobre amores con jovencitas, con colegialas. Pero no se sanciona el pensamiento sino la acción, el hecho. No la fantasía - de la cual no siempre somos conscientes y manejamos a voluntadsino la conducta externa.
Es así que llegamos a la escena donde Walter le responde a su psicólogo a lo que podría ser un test de asociación de palabras, al escuchar los estímulos: niña, bonita, placer, y piensa en su hermana menor, en su hermanita de la infancia y la siguiente escena que aparece en su mente es ella durmiendo en la cama de él, ella tiene 4 años en ese momento y Walter 6 años. ¿Qué están haciendo? le pregunta astutamente el psicólogo. La respuesta toscamente dada es "una siesta" y Walter se altera y no quiere seguir hablando de eso, ¿por qué? ¿Qué fue lo que ocurrió? Eran solamente niños acariciándose pero ahora Walter lo ve mal, y se siente culpable por tomar cierta ventaja sobre su hermana. En esta escena estamos hablando de dos niños pre escolares que hacen una siesta juntos en la misma cama. Se tocan, se rozan, se huelen, se sienten. La consideración freudiana del niño como sujeto a una "disposición perversa polimorfica" (Freud, 1905/1976 p. 173), si bien es algo dura, es contundente para entender la potencialidad de los niños para satisfacer sus curiosidades y necesidades. Se miran, huelen, tocan, sienten, rozan, y se sienten bien. ¿Era ya por entonces Walter un niño enfermo? ¿o era simplemente un niño que se sentía muy bien de estar cerca de su querida hermana? Los psicoterapeutas sabemos que si bien el pasado influye en el presente, pues el presente también influye en el pasado. Esto debido a que los seres humanos revisamos y revaloramos nuestros recuerdos, nuestras vivencias son reconsideradas, son retocadas en cada presente. Walter ( $\mathrm{y}$ posiblemente su hermana) asumen como un acto de abuso este tipo de experiencias comunes. Cierto es que Walter no nos cuenta si con su hermana pasó algo más. Hoy, su hermana sigue enojada con él y no va a su encuentro terminada su larga condena. ¿Por qué? ¿pasó algo más penoso para ella?

Un detalle a considerar es cuando Walter abre los ojos y ve al terapeuta sentado a sus espaldas, "no me gusta que nadie esté sentado a mis espaldas" dice alterado, podemos encontrar nuevamente un mecanismo de proyección acá, pues era Walter quien se colocaba detrás de su hermana para olerla y sobarse con ella ¿o ya antes de esos recuerdos con su hermana alguien se sentó detrás de él? El psicólogo 
insiste "¿qué pasaba cuándo estabas con ella?" La respuesta es "solo olía su cabello, nada más". Vemos acá a Walter embargado con una fuerte emoción, con expresión de llanto que intenta reprimir. El recuerdo de un olor, una sensación olfativa que posiblemente viene cargada de asociaciones que Walter reprime. ¿qué hay detrás de ese olor? ¿A qué -o a quién- te recuerda ese olor? Serían preguntas que yo haría. Curiosamente, luego de esta sesión llega a casa y repite la escena con su pareja, con Vickie, le pide que se siente sobre sus piernas, estando en la cama ambos en ropa interior, él la sujeta por detrás, se soba con ella y le huele el cabello, pero esta vez el goce va acompañado de la culpa, la angustia moral.

En la película, un policía tiene el encargo de supervisar que todo ande tranquilo con Walter ahora que está en libertad, es el Sargento Lucas, quien en la primera visita le recuerda que Walter es solo un pedazo de mierda, una aberración, inclusive su vida no vale nada pudiendo matarlo con total impunidad. Esto merece ser comentado. Una situación de confrontación a este nivel entre el rudo policía y el ex reo lo que consigue es llevarlo a Walter nuevamente y ferozmente al pasado, confirmándole que es un enfermo que no va a mejorar nunca, su condición es esa, enfermo, mierda, basura, de ahí que su pregunta ¿cuándo seré normal? se responde con un nunca. Pienso en cuanto duran algunas condenas, la de Walter está claro que mucho más de doce años. Walter sigue preso. Y esto lo podríamos considerar en muchos otros tipos de reos que al salir de prisión, siguen siendo considerados unos parias por toda la sociedad. Así es muy complicado readaptarse al grupo.

Mientras todo esto pasa, un nuevo acosador aparece en escena en las calles del vecindario de Walter, un pedófilo seductor de niños denunciado en otro Estado por abuso a un menor, inicia una insana conquista infantil. Esta situación perturba al aparente indiferente Walter, posiblemente se siente identificado con él o proyecta en este sujeto lo que no acepta de su propia conducta. Recordemos que en una escena el protagonista cae al suelo destruyendo unos papeles y repitiéndose eso de "yo no soy como ellos", "yo no soy como ellos" en referencia a los criminales sexuales de los cuáles le acaba de hablar el sargento Lucas. Una escena nos muestra a Walter en un Centro Comercial siguiendo a dos jóvenes adolescentes sin saber muy bien por qué $y$ para qué. Nada ocurrió y luego lo comentó en su sesión de psicoterapia. ¿Estaría probándose a sí mismo? Nunca sabremos si de haberse dado algunas condiciones él hubiera ido más allá.

\section{EL DEBATE ENTRE LO CONDUCTUAL Y LO MENTAL}

El comportamiento y el pensamiento/deseo. ¿Qué hace que una persona sea lo que es? ¿La conducta o el pensamiento? ¿Porque Walter ya no lo hace ya no es abusador de menores? ¿o porque ya no lo desea? ¿Somos lo que hacemos o somos lo que pensamos? ¿o ambos? ¿terapia conductual o psicoterapia? ¿Nuevos hábitos y estímulos o una revisión de lo más profundo de sus recuerdos infantiles $y$ de su mente inconsciente? A nosotros nos enjuician y nos encarcelan por lo que hacemos, ¿qué pasaría si lo hicieran por nuestros pensamientos? Las cárceles estarían llenas. Otro tema para el debate, ćcura la cárcel el desorden psicológico?, ¿cuál es la utilidad de las cárceles? ¿están las cárceles preparadas no solo para tener retenidos a sus involuntarios huéspedes sino para readaptarlos a la vida extramuros?

Walter es una paradoja. Lo encarcelan doce años por su conducta impropia, sale y ahora se le sigue considerando un pedófilo ya no por su conducta presente sino por su pasado. En cuanto a su experiencia subjetiva hay una disonancia pues pareciera que sus deseos sexuales infantiles persisten aún y eso sumado a sus remordimientos y recuerdos lo mantienen en un estado de malestar continuo. Podría llegar Walter a desear volver a prisión pues sería "el lugar al que pertenece", en cambio ahora está sin estar, sin pertenecer, sin ser totalmente recibido.

Vickie, la co-protagonista, se vuelve una suerte de salvadora de Walter. Ella le permite experimentar algo de intimidad, le brinda y 
le permite dar caricias ${ }^{7}$ (en el sentido de Eric Berne), le permite sentirse acompañado, lo acepta, no lo juzga, (en el sentido de Carl Rogers) y eso siempre será sanador.

Eric Berne nos recuerda (Berne, 1988) que los seres humanos tenemos necesidades de reconocimiento y estas se atienden con estímulos táctiles o sociales, que en Análisis Transaccional (A.T.) se llaman las caricias. La caricia es aquí la unidad de reconocimiento, ejemplo un saludo, una palabra gentil, un obsequio, un beso. Las caricias tienen en común que logran hacer que la persona que las recibe se siente viva y que los demás reconozcan su existencia, sea porque la elogian sinceramente (caricias positivas), la adulan, por ejemplo para manipularla, (falsas caricias positivas), o la rechazan, insultan o hasta pegan (caricias negativas).

Por su parte, Carl Rogers nos enseñó en psicoterapia que la relación entre el paciente o cliente y el psicoterapeuta es el elemento primordial para que se desarrolle la mejora del paciente. Mediante el uso de la escucha empática, la disposición a acompañarlo y no juzgarlo y la aceptación incondicional, se intenta promover un ambiente cálido y libre de amenazas donde el cliente pueda expresarse libremente (Rogers, 1997).

\section{WALTER PIERDE LA CONFIANZA:}

El recuerda que la estadística menciona que la mayoría de gente con trastorno pedófilo regresan a prisión. ¿A qué se debe esto? ¿Profecía autocumplida ${ }^{8}$ al mismo estrilo del experimento de las escuelas del psicólogo Robert Rosenthal? ¿desesperanza aprendida? ${ }^{9}$ O tal vez la elaboración de un constructo personal sumado a esas representaciones sociales de los enfermos sexuales que el también estaría considerando correctas.

\section{LA PSICOLOGÍA DE VICKIE}

Dentro de la psicología de Vickie, su actual pareja, debemos indicar que ella sobrevivió en una familia de tres varones. Ella misma cuenta que fue penetrada reiteradamente por sus tres hermanos, siendo niña. Esto es interesante, ella puede ver en Walter a alguno de sus hermanos, se identifica con sus agresores por medio de él. Inconscientemente ella podría sentirse que fue cómplice de la conducta abusiva y egoísta de sus hermanos llegando a apoyarlos como defensa desesperada. ¿Cuál pudo ser la causa? Es un tema delicado de tratar, cle gustó este tipo de relación con ellos? Era la forma de sentirse querida, apreciada, tomada en cuenta, quizá. Era lo "menos malo" dentro de lo malo. De ellos dice que "son hombres fuertes y gentiles con sus familias" ¿y ella? De pronto, ella es la oveja negra, la mentirosa, el chivo expiatorio de esa familia disfuncional. Al contarle su historia a Walter, jamás menciona a sus padres. ¿Dónde estaban? Quizá no estaban o no le dieron ninguna importancia, dejándola a merced de los impulsos y carencias de control sexual de sus hermanos. Probablemente para que los tres la abusaran era porque, inconscientemente, esa era la indicación de sus padres. Ante esta soledad y desamparo, el comercio sexual pudo ser percibido como una forma de cariño. ¿El primero en abusar de ella fue su padre? Surge la inquietud de investigarlo.

\section{¿ELIGE UN PEDÓFILO SER PEDÓFILO? ¿ELIGE SIEMPRE UNO LO QUE ES?}

Incumpliendo el reglamento Walter se acerca a una niña en la calle y entabla conversación. Podemos ver una conversación de niños. Con

\footnotetext{
7 Algo que Berne puntualiza con mucha razón es que las más de las personas pueden llegar a preferir recibir caricias negativas a estar sin estimulación y reconocimiento. Como en aquél vals peruano "Ódiame" del compositor Rafael Otero López, que inspirado en un soneto titulado "Último ruego" de Federico Barreto, nos dice en la primera parte de la canción: "Ódiame por piedad yo te lo pido, ódiame sin medida ni clemencia; odio quiero más que indiferencia, porque el rencor hiere menos que el olvido".

8 Una profecía autocumplida es una expectativa que convertida en acciones, incita a las personas a actuar en formas que hacen que la expectativa previa se vuelva cierta.

9 Desesperanza aprendida es un estado en que un organismo ya no emite respuestas para escapar de estímulos adversivos debido a experiencias pasadas de escape o confrontación que resultaron reiteradamente defectuosos o ineficaces. El sujeto sencillamente ya no hace nada. Es la percepción de una imposibilidad de lograr cualquier cosa, la idea de que ya no hay nada que hacer, ni ahora ni nunca. Se verá entonces lo peligroso de este estado.
} 
preguntas y respuestas, simples, juguetonas. Pareciera que Walter se quedó atascado en su niñez. Parece cómodo con esta niña, pareciera que puede manejar esta situación. No ocurre nada pues la niña decide irse a casa.

Mientras tanto al publicarse en el trabajo su expediente criminal, $\mathrm{y}$ viendo que ahora el acoso permanente del cual iba a ser, decide dejar el trabajo y lo primero que hace es ir a un parque encontrando a una niña solitaria que había conocido en otra oportunidad. Esta vez inicia un diálogo que terminará con su pedido directo de ir a un lugar más tranquilo para que se siente en sus piernas, reconociendo que lo disfrutaría ¿Por qué Walter hace esto? ¿Es un fuerte deseo, que ahora en situación de estrés ya no puede controlar o una forma de ser finalmente arrestado y terminar encerrado posiblemente de por vida? "Cumplir la profecía, el monstruo debe ser castigado, nunca voy a cambiar, es lo que merezco cacaso diría su mente si pudiera hablar?, además la estadística dice que gente como yo suele regresar a prisión". Nos damos cuenta que esta niña del parque es víctima de un padre que la manosea y la acaricia. ¿Notan amigos lectores como los guiones de vida se buscan? ¿cómo detrás de mucha fortuna o "mala suerte" existen poderosas causas no conscientes que empujan a que ciertos hechos ocurran? Piensen por un momento en muchos "accidentes" o "destinos" de los cuáles hablan las personas sin mayor reflexión. Un análisis psicológico exhaustivo nos da otras explicaciones para ciertos eventos.

Al ver mortificada a la niña, esto fastidia a Walter y lo pone frente a un espejo, lo hace tomar consciencia del daño que está por realizar, despertar de su trance sexual infantil $y$ fijarse en el dolor que conductas como la suya pueden generar, y de hecho generaron. Desiste de seguir avanzando con la niña y regresa a casa.

Fastidiado por esto y de regreso a su departamento, encuentra al adulto acosador de niños bajando de su auto a una de sus víctimas, habiendo consumado ya la perversa necesidad. Walter lo confronta y lo agrede físicamente, dañándolo seriamente, viéndose reflejado en él mientras lo hace, por medio de unas rápidas imágenes a la manera de alucinaciones visuales autoscópicas. ${ }^{10}$

Al finalizar la película vemos que Walter se va a vivir con Vickie, saliendo del vecindario donde está la escuela primaria, para comenzar otra vez. Consigue una primera reunión con su hermana, reunión que no fue muy exitosa pues se sigue sintiendo lastimada y furiosa. Tomará tiempo, se dice Walter. Pero no solo tomará tiempo que su hermana quiera perdonarlo, sino que tomará tiempo que Walter sane sus heridas y tomará tiempo que la sociedad crea en una segunda oportunidad para las personas que, como Walter, desean ser tratados alguna vez como normales.

\section{CONCLUSIONES}

1. Cuandohemospasado ciertas experiencias que no hemos entendido, procesado $y$ digerido existe una tendencia a volver sobre el punto, una inquietud por volver a hacer lo mismo o comprometernos en situaciones parecidas. Como el protagonista Walter que regresa de prisión y va a vivir al frente de una escuela primaria.

2. La pedofilia es una parafilia que conlleva durante un período de al menos 6 meses, fantasías sexuales recurrentes y altamente excitantes, impulsos sexuales o comportamientos que implican actividad sexual con niños prepúberes o niños algo mayores (generalmente de 13 años o menos). Las fantasías, los impulsos sexuales o los comportamientos provocan malestar clínicamente significativo o deterioro social, laboral o de otras áreas importantes de la actividad del individuo.

3. No existe una sola causa para la pedofilia. Muchos pedófilos fueron en su infancia

10 La alucinación de uno mismo, o autoscopía, se define como aquella alteración de la percepción, consistente en verse a sí mismo como a un doble. La pueden experimentar personas sanas que se encuentren en un estado de fatiga excesiva, intoxicadas por algún tipo de droga, o que sufren de patologías como la epilepsia o tumores cerebrales (Fuente: http://www. medicinaycultura.org.ar/24/Articulo_05.htm) 
sujetos abusados sexualmente. En otros existe un bloqueo en el desarrollo psicosexual normal que lleva a que se les haga muy complicado relacionarse con personas de su propia edad, también podemos encontrar en ellos una identificación infantil muy fuerte, una personalidad inmadura y una baja seguridad en sí mismos. Igualmente, se aduce la posibilidad de la existencia de trastornos de personalidad como factores importantes: deficiencias en el control de los impulsos y en la imagen personal, tanto por una educación sexual negativa y culpabilizadora como por unos modelos familiares no adecuados.

4. Si bien el pasado influye en el presente, pues el presente también influye en el pasado. Esto debido a que los seres humanos revisamos $y$ revaloramos nuestros recuerdos, nuestras vivencias son reconsideradas, son retocadas en cada presente. $\mathrm{Y}$ esta es una valiosa oportunidad en el campo psicoterapéutico. No estamos necesariamente esclavos de nuestro pasado. No siempre al menos.

5. Según algunos estudiosos en este tema, no se pueden cambiar las preferencias sexuales ni la orientación hacia un sexo determinado, ni la predilección por determinadas prácticas sexuales. Lo que deben hacer los pedófilos es aprender a controlar sus apetencias sexuales con el fin de no perjudicar ni a otros ni a sí mismos. El pedófilo puede excitarse ante la visión de un niño pero debe aprender a controlar el impulso de abusar de él. Otras propuestas psicoterapias buscan que el sujeto logre encontrar las causas que estarían detrás de su preferencia sexual, enfrentarlas, ser conscientes de ellas y con ayuda psicológico profesional alcanzar madurez sexual así como mejorar sus habilidades sociales lo que les permitirá relacionarse con iguales y tener mejores estrategias de seducción y enamoramiento para poder buscar parejas adecuadas $y$ satisfacer sus necesidades afectivas sexuales con ellas.

6. Finalmente, hoy el cine es cada vez más sofisticado en el trabajo de los personajes y con razón es considerado uno de los grandes artes de la humanidad. Pero, ¿qué ha retratado el cine -con sus directores, guionistas, actores y técnicos- si no ha sido el quehacer humano? La conducta, las acciones humanas, las dinámicas intra e interpersonales, "nuestros ángeles y nuestros demonios", en una palabra, la psique humana. Considero -como profesor también- que a través de las películas encontramos un pretexto para prolongar la docencia y practicar la observación, el análisis, el diagnóstico y el pronóstico psíquico y social. Cada película se mueve dentro de una temática y el análisis de esta película en particular The Woodsman (o El leñador) nos ha permitido continuar trabajando psicológicamente con uno de los problemas más difíciles en material sexual. 


\section{REFERENCIAS}

American Psychiatric Association. (2003) DSM-IV-TR: Breviario: Criterios diagnósticos. Barcelona: Masson.

Berne, E. (1985) Juegos que juega la gente. México: Diana S. A.

Berne. E. (1988) ¿Qué dice usted después de decir hola? Caracas: Grijalbo.

Freud, S. (1976) Tres ensayos de una teoría sexual. Punto II: La sexualidad infantil. En Obras Completas, Volumen VII. 6ta. Reimpresión. Buenos Aires: Amorrortu Editores.

Kassell, N. (Director), Kassell, N. y Fechter, S. (Guionistas). (2004) The Woodsman (El leñador) [Película]. EEUU: Universal Pictures.

Organización Mundial de la Salud. (1992) CIE-10. Trastornos Mentales y del Comportamiento. Décima Revisión de la Clasificación Internacional de las Enfermedades. Descripciones Clínicas y pautas para el diagnóstico. Ginebra.

Real Academia Española. (2001) Diccionario de la Lengua Española. Vigésima Segunda Edición. Disponible en Internet http://www.rae.es/rae.html

Rogers, C. (1997). Psicoterapia centrada en el cliente. Barcelona: Ediciones Paidós Ibérica. 